\title{
The research on the apparent viscosity model of sludge
}

\author{
Y. Z. Xue ${ }^{1, a^{*}}$, B. Lou ${ }^{1, b}$, W. Qian ${ }^{1, c}$ \\ ${ }^{1}$ School of electric power, South China University of Technology, Guangzhou, 510640, China \\ a1044904866@qq.com, 'loubo@scut.edu.cn, 'cqianwei8989@foxmail.com
}

Keywords: Sludge, Apparent viscosity, Viscous model

\begin{abstract}
The viscosity of sludge not only affects its transport properties, but also the drying efficiency. In the paper, the sludge property of apparent viscosity was studied with the different types of sludge , moisture content of sludge and temperature with the help of NDJ series digital viscometer. The results show that the different content of organic matter between municipal sludge and dyeing sludge makes the viscosity of municipal sludge much larger than dyeing sludge's, and the difference increases with the decrease of respective moisture content of the two kinds of sludge. The apparent viscosity of sludge shows exponential growth in the form of $\mu=f \exp (g w)$ with the decrease of the moisture content, and coefficient of $g$ is approximately the constant value under different temperatures and different moisture content .In addition, the values of municipal sludge and dyeing sludge are -49.64 and -25.10 respectively. In the meanwhile, indicating that the models of coefficient $f$ of municipal sludge and dyeing sludge are accordance with ExpDec1 model and Log3P1 model respectively, and finally model equations are obtained between apparent viscosity of sludge and moisture content and temperature.
\end{abstract}

\section{Introduction}

As the world's cities and its population continues to grow, the amount of sewage and sludge generation also increases. The annual total amount of sludge production of China's sewage treatment plant amounted to over 35 million tons in 2011 and maintain an annual growth rate of $10 \%$. It is predicted that by 2020, the total amount of sludge will exceed 60 million tons annually [1], so how to dispose of sludge safely will become one of the major environmental issues which is facing in China as a developing country. Bacteria and parasites as well as heavy metals in Sludge, if they cannot be safely dealt with, will cause environmental pollution and become potential security issues [2-4]. Volume reduction, stabilization, harmlessness and resourcefulness are the targets of sludge treatment and disposal. Sludge drying is one of the ideal ways for the safety treatment of sludge

The diffusion coefficient of water in the sludge hinders the rate of sludge drying, and the relationship between the moisture diffusion coefficient and the apparent viscosity of the sludge is inverse [5]. Therefore, the rate of sludge drying is indirectly affected by the apparent viscosity coefficient of the sludge. In addition, when the viscosity is too large, especially the moisture content of 60\%-80\%, it is prone to sludge adhering behavior, affecting its transport and the safe and economic operation of drying equipment [6-8]. It can be seen that the viscosity of sludge has a significant effect on its transport and drying process of sludge, and it is worthwhile to study the viscosity of sludge in practical application.

Rheological properties of viscous fluids are usually expressed as the relationship between shear stress and shear rate, and in engineering it is often expressed by viscosity. Researchers have studied the rheological properties of sludge, knowing that the sludge is non-Newtonian fluid with the property of shear thinning, and proposed a series of model [9-14]. In addition, the rheological parameters of sludge have something to do with the extent of sludge dewatering [15], and at the same time it points out that the relationship between the sludge viscosity and suspended matter concentration is in line with the exponential model $[9,10,16]$. But the previous research on the quantitative relationship between the apparent viscosity of the sludge and the types, moisture content as well as temperature of the sludge is still lacking. In order to provide a theoretical basis for the 
sludge transportation and drying process, the paper mainly studies the effect of types, moisture content and temperature of sludge on the apparent viscosity of the sludge, obtaining a certain rule and establishing theoretical models.

\section{Experiment}

Guangzhou urban sewage is required to take the biochemical treatment method. The experimental sludge samples used in our study came from the municipal dewatering digested sludge of a sewage treatment plant in Guangzhou and dyeing sludge of a textile factory. The moisture contents of them are about $84 \%$ and $66 \%$ respectively.

Experimental Devices. The experimental devices of the experiment are: NDJ series digital viscometer, digital thermostat water bath with the heating temperature range from normal temperature to $100^{\circ} \mathrm{C}$, glass thermometer with range of $200{ }^{\circ} \mathrm{C}$, beaker, square crucible, blast drying oven etc.

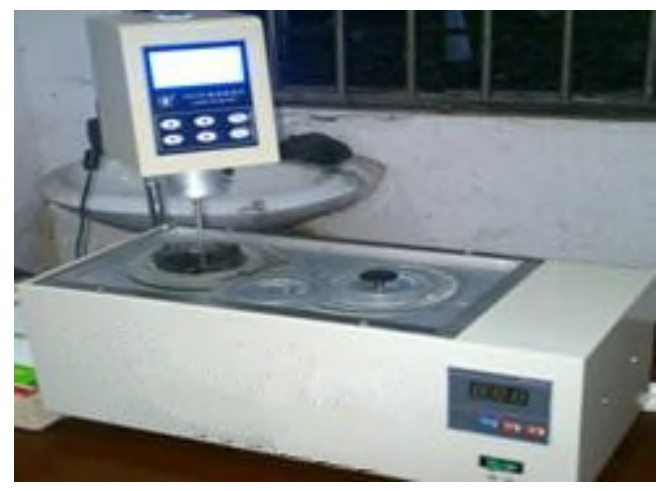

(a)digital viscometer and thermostat water bath

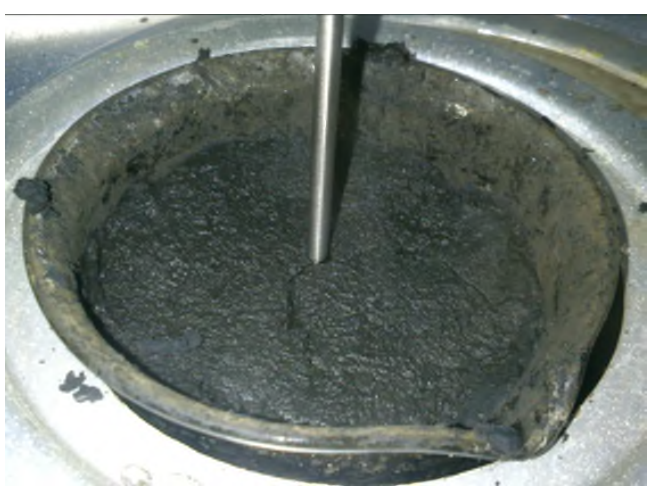

(b)the measurement of the viscosity of dyeing sludge in the beaker

Fig. 1 The physical map of device for measurement of the sludge's viscosity.

In the experiment, NDJ-8S series digital viscometer is used to measure absolute viscosity of Newton fluid and the apparent viscosity of non- Newton fluid. The digital viscometer rotates at a constant speed by rotor which is driven by the motor through the variable speed belt, causing the fluid produces a viscous torque on the rotor. Then viscous torque is detected by the sensor, and finally the signal of sensor turn into the viscosity of the fluid by the processor. In addition, viscometer has standard rotors, and its measurement range is from 1 to $2 \times 10^{6} \mathrm{mPa} . \mathrm{s}$ with the measurement accuracy of $\pm 2 \%$.

Experiment Method. The experimental sludge was placed in a beaker the diameter of $60 \mathrm{~mm}$ and height of $120 \mathrm{~mm}$, then is placed in digital thermostat water bath. The temperature of sludge was set and the instrument was carefully adjusted to the horizontal position. The appropriate rotor was selected and the height of rotor in the beaker was adjusted to be parallel with the tested sludge. As the sludge is non-Newtonian fluid, in the determination, the experiment should be strictly controlled over the sludge type, the speed and duration of rotor in order to obtain comparable results.

\section{Results and Analysis}

In the preparatory experiment of municipal dewatering sludge, it is found that the sludge with high moisture content has better fluid properties, and the sludge loses characteristics when the moisture content of the sludge is reduced to below $50 \%$. In this paper, only the sludge with fluid properties was studied.

Effect of Sludge Types on Apparent Viscosity. For municipal sludge, $15^{\circ} \mathrm{C}, 21^{\circ} \mathrm{C}, 30^{\circ} \mathrm{C}, 50^{\circ} \mathrm{C}$, $70^{\circ} \mathrm{C}$ and $90^{\circ} \mathrm{C}$ several different temperature conditions were studied; for dyeing sludge, the temperature conditions were $15^{\circ} \mathrm{C}, 25^{\circ} \mathrm{C}, 36^{\circ} \mathrm{C}, 50^{\circ} \mathrm{C}, 72^{\circ} \mathrm{C}$ and $90^{\circ} \mathrm{C}$. Fig. 2 show the apparent 
viscosity curves of municipal sludge and dyeing sludge at the common temperature of $15^{\circ} \mathrm{C}, 50^{\circ} \mathrm{C}$ and $90^{\circ} \mathrm{C}$. It can be seen from figure that the apparent viscosity of municipal sludge is much larger than that of dyeing sludge under the same wet basis moisture content. For example, when the moisture content is $87 \%$, the apparent viscosity of $90^{\circ} \mathrm{C}$ municipal sludge is about $27880 \mathrm{mPa}$.s, while the apparent viscosity of $90^{\circ} \mathrm{C}$ dyeing sludge is about $716 \mathrm{mPa}$.s. Besides that, the difference increases with the decrease of respective moisture content of the two kinds of sludge. It is obvious that the viscosity has a great relationship with the natural properties of sludge. Compared with the municipal sludge, the organic matter content of dyeing sludge is low, causing dyeing sludge possessing the properties of large group particles, poor water retention of particle and easy precipitation, so that under the same moisture content, the viscosity of dyeing sludge is far less than the municipal sludge "s. It can be seen from (c) in Fig. 2 that when the moisture content of municipal sludge is less than 88\%, its apparent viscosity begins to increase sharply, but on the other hand, the moisture content of dyeing sludge is less than $74 \%$. Therefore, inflection point of increase is also different due to kinds of sludge.

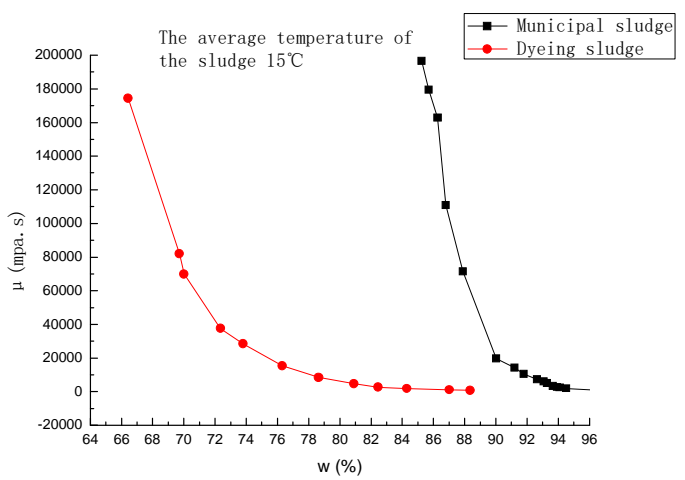

(a) the average temperature of the sludge $15^{\circ} \mathrm{C}$

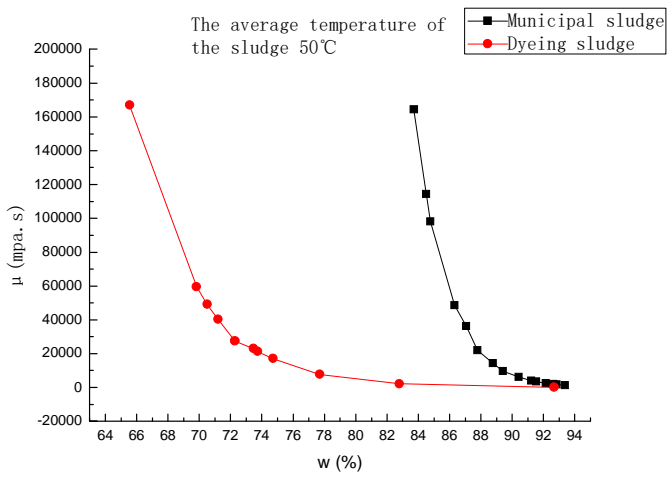

(b) the average temperature of the sludge $50^{\circ} \mathrm{C}$

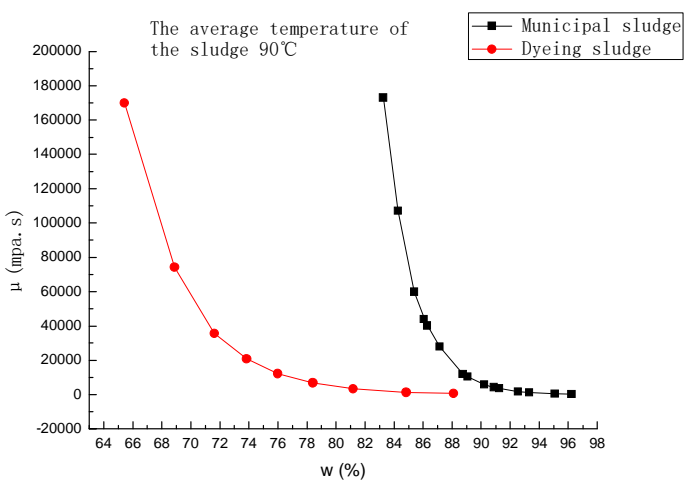

(c) the average temperature of the sludge $90^{\circ} \mathrm{C}$

Fig. 2 Comparison of apparent viscosity between municipal sludge and dyeing sludge versus wet basis moisture at different temperatures 
Effect of Moisture Content on Sludge Apparent Viscosity. As the curves showed in Fig. 3 and Fig. 4, the apparent viscosity versus the moisture content expressed on the wet basis, obtained from municipal sludge and dyeing sludge respectively. The apparent viscosity values of the two sludge increase with the reduction of moisture content. For municipal sludge, the apparent viscosity at the high moisture content (over $88 \%$ ) is small and its change is slow, but with the moisture content decreased to below $88 \%$, the apparent viscosity of municipal sludge increase rapidly, which is similar to the exponential law growth. While the moisture content of dyeing sludge decreases to $76 \%$, the apparent viscosity value begins to increase rapidly. Fig. 3 and Fig. 4 also indicate that for the same sludge under the same moisture content conditions, the viscosity value decreased with the increase of sludge temperature, and the temperature has greater effect on municipal sludge than the dyeing sludge's. As we all know, water viscosity decrease with the increase of temperature, which leads to the reduction of sludge apparent viscosity too.

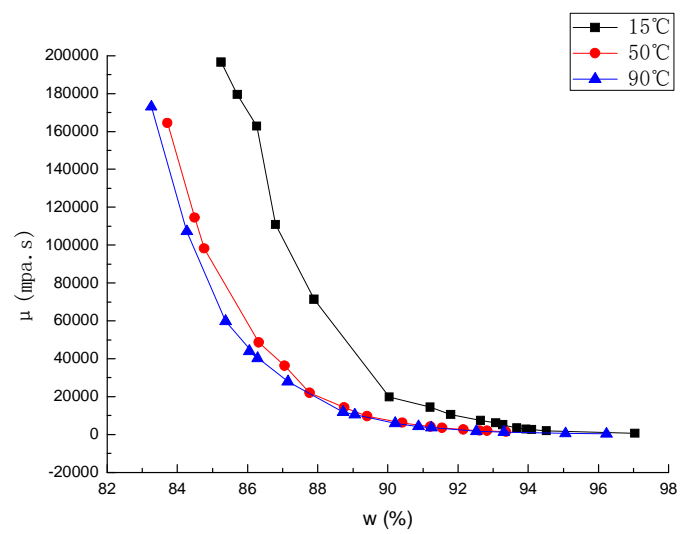

Fig. 3 The apparent viscosity of municipal sludge versus wet basis moisture content.

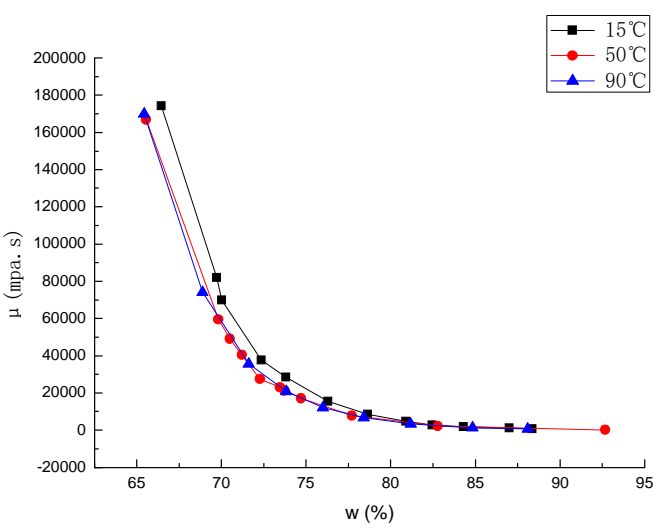

Fig. 4 The apparent viscosity of municipal sludge versus wet basis moisture content.

In the common model of sludge viscosity and concentration, the exponential model is most widely used, and in comparison with clean water, the expression of the sludge is as follows 오류! 참조 원본을 찾을 수 없습니다.:

$$
\mu=\mu_{0} \lambda \exp (\beta \cdot M L S S)
$$

where, $\mu$ (mPa.s) is the viscosity of sludge; $\mu_{0}$ (mPa.s) is the viscosity of clean water; $\lambda$ is a coefficient doing with temperature; $\beta$ is a constant; $\operatorname{MLSS}(\mathrm{g} / \mathrm{L})$ which is related to moisture content is suspended matter concentration of sludge.

After analysis, the simplified model equation we can get from (1) is:

$\mu=f \exp (g w)$ 
where, $f$ and $g$ are two coefficients related to temperature and moisture content; $w(\%)$ is the moisture weight content of sludge.

The coefficient $f$ and $g$, which are related to the wet basis moisture content of sludge and the temperature of sludge, are derived from the fitting by the data of contrast experiment with the help of Origin Software, and the data is sorted out in Table 1.

\section{Apparent Viscous Models}

In this paper, the fitting process of the model is as follows: the logarithm is taken on the two sides of the Eq. 2, getting

$$
\ln \mu=\ln f+g w
$$

Appropriate $f$ and $g$ are fitted out linear fitting, making sure that $\ln \mu$ is linear with $w$ and its correlation coefficient $\mathrm{R}^{2}$ is max. The experimental and fitted values of viscosity of municipal sludge at $50^{\circ} \mathrm{C}$ and dyeing sludge at $90{ }^{\circ} \mathrm{C}$ are shown in Fig. 5 and Fig. 6, respectively.

Table 1. Fitting results of relationship between water content and viscosity.

\begin{tabular}{cccc}
\hline$\mu=f$ exp $(g w)$ & $f$ & $g$ & $\mathrm{R}^{2}$ \\
\hline $15^{\circ} \mathrm{C}$ municipal sludge & $6.08 \mathrm{E} 23$ & -49.70 & 0.9933 \\
\hline $21^{\circ} \mathrm{C}$ municipal sludge & $4.81 \mathrm{E} 23$ & -49.92 & 0.9971 \\
\hline $30^{\circ} \mathrm{C}$ municipal sludge & $3.85 \mathrm{E} 23$ & -49.83 & 0.9975 \\
\hline $50^{\circ} \mathrm{C}$ municipal sludge & $1.93 \mathrm{E} 23$ & -49.66 & 0.9993 \\
\hline $70^{\circ} \mathrm{C}$ municipal sludge & $1.20 \mathrm{E} 23$ & -49.71 & 0.9815 \\
\hline $90^{\circ} \mathrm{C}$ municipal sludge & $9.21 \mathrm{E} 22$ & -49.01 & 0.9998 \\
\hline & & & \\
\hline $15^{\circ} \mathrm{C}$ dyeing sludge & $2.97 \mathrm{E} 12$ & -25.05 & 0.9723 \\
\hline $25^{\circ} \mathrm{C}$ dyeing sludge & $2.61 \mathrm{E} 12$ & -25.16 & 0.9562 \\
\hline $36^{\circ} \mathrm{C}$ dyeing sludge & $2.46 \mathrm{E} 12$ & -25.11 & 0.9486 \\
\hline $50^{\circ} \mathrm{C}$ dyeing sludge & $2.35 \mathrm{E} 12$ & -25.12 & 0.9995 \\
\hline $72^{\circ} \mathrm{C}$ dyeing sludge & $2.28 \mathrm{E} 12$ & -25.14 & 0.9868 \\
\hline $90^{\circ} \mathrm{C}$ dyeing sludge & $2.21 \mathrm{E} 12$ & -25.03 & 0.9933 \\
\hline
\end{tabular}

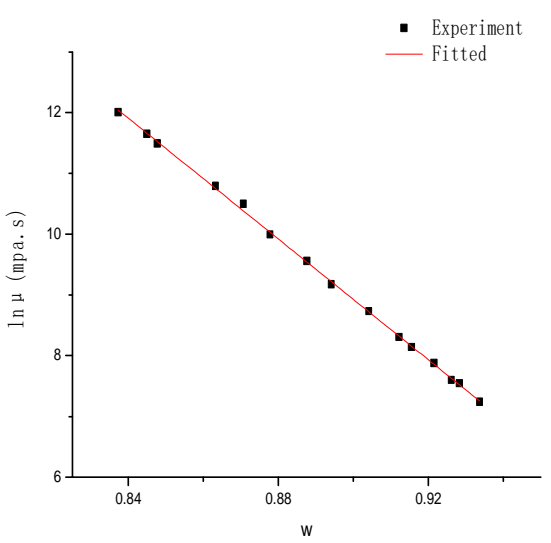

Fig. 5 Experimental and fitting value of municipal sludge apparent viscosity versus wet basis moisture at $50^{\circ} \mathrm{C}$

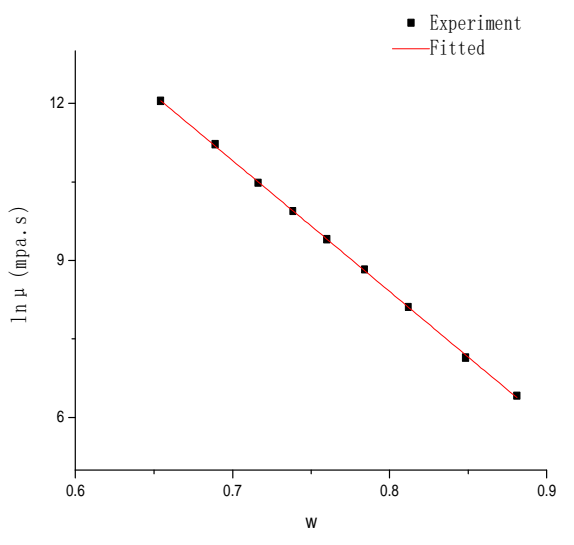

Fig. 6 Experimental and fitting value of dyeing sludge apparent viscosity versus wet basis moisture at $90^{\circ} \mathrm{C}$.

Through the analysis of the results in table1, for the same kind of sludge, the values of the coefficient $g$ have only a little difference, and it can be approximately considered as a constant, which don't vary with temperature and moisture content. As sludge is a non-Newtonian fluid, its rheological properties can be described as Bingham model and power-law model [18, 19]. So, considered the 
coefficient $g$ as a constant, the averages of coefficient $g$ of municipal sludge and dyeing sludge are -49.64 and -25.10 respectively.

The apparent viscosity of sludge decreased with the increase of temperature. As for what kind of quantitative relationship shows between the apparent viscosity of the sludge and the average temperature within the sludge, the relationship can be described Nicky et al [20,21]. Research shows that the influence of temperature on the viscosity coefficient is mainly embodied in $f$, a coefficient related to temperature. In order to further get a complete Eq. (2), Fig. 7 and Fig. 8 are plotted to show the relationship between the coefficient $f$ and temperature further, which are fitted to the exponential or logarithmic law after careful analysis, and the results, as shown in Table 2, are fitted by using multi-exponential and logarithmic models.

Table 2. Results of the relationship between temperature $\mathrm{T}(\mathrm{K})$ and the coefficient $f$.

\begin{tabular}{|c|c|c|c|}
\hline $\begin{array}{c}\text { Sludge } \\
\text { type }\end{array}$ & $\begin{array}{c}\text { Equation } \\
\text { name }\end{array}$ & Equation & $\mathrm{R}^{2}$ \\
\hline \multirow{3}{*}{$\begin{array}{l}\text { municipal } \\
\text { sludge }\end{array}$} & ExpDec1 & $f=5.392 E 22+2.766 E 28 x \exp \left(-\frac{T}{26.623}\right)$ & 0.9955 \\
\hline & ExpDec2 & $\begin{array}{c}f=5.392 E 22+1.383 E 28 x \exp \left(-\frac{T}{26.623}\right)+ \\
1.383 E 28 x \exp \left(-\frac{T}{25.623}\right)\end{array}$ & 0.9865 \\
\hline & Log3p1 & $f=1.070 E 24-2.265 E 23 x \ln (T-280.572)$ & 0.9861 \\
\hline \multirow{3}{*}{$\begin{array}{l}\text { dyeing } \\
\text { sludge }\end{array}$} & ExpDec1 & $f=2.232 E 12+1.129 E 19 x \exp \left(-\frac{T}{17.402}\right)$ & 0.9868 \\
\hline & ExpDec2 & $\begin{array}{c}f=2.065 E 12+5.208 E 27 x \exp \left(-\frac{T}{7.760}\right)+ \\
5.813 E 13 x \exp \left(-\frac{T}{60.972}\right)\end{array}$ & 0.9962 \\
\hline & $\log 3 \mathrm{p} 1$ & $f=3.127 E 12-2.109 E 11 x \ln (T-286.048)$ & 0.9979 \\
\hline
\end{tabular}

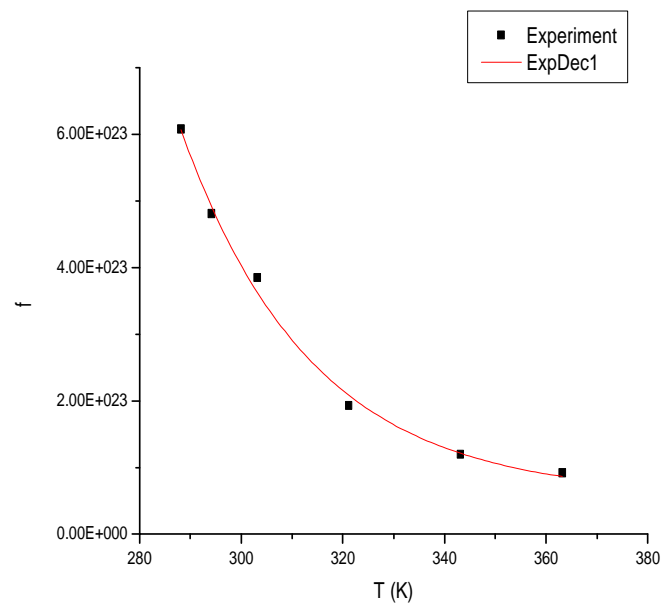

Fig.7 Experimental and fitting values of the coefficient $f$ of municipal sludge apparent viscosity versus temperature.

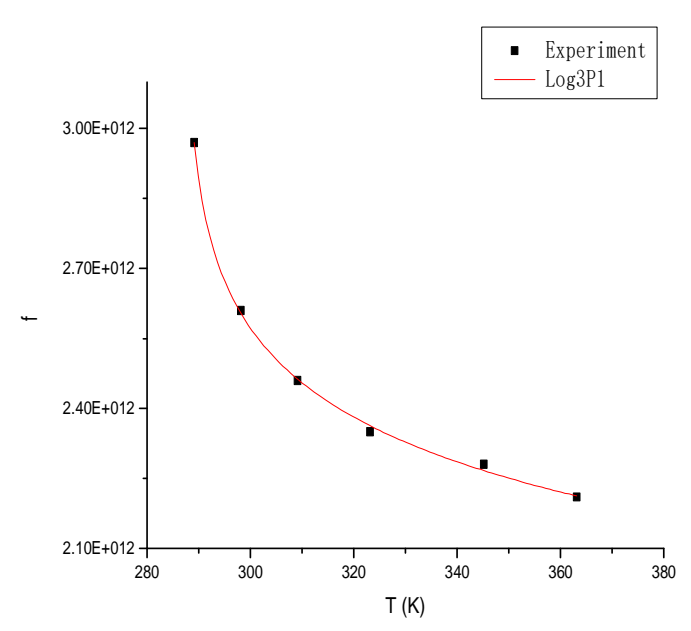

Fig. 8 Experimental and fitting values of the coefficient $f$ of dyeing sludge apparent viscosity versus temperature. 
Known from Table 2, the model of ExpeDec1 is better with differentiate coefficient $\mathrm{R}^{2}$ close to 1 after analyzing the fitting results of $f$ and temperature of municipal sludge, and the model formula of $\mu$ is selected as follows:

$$
\mu=\left(5.392 E 22+2.766 E 28 x \exp \left(-\frac{T}{26.623}\right)\right) \exp (-49.64 w)
$$

Similarly, for dyeing sludge, the model of $\log 3 \mathrm{P} 1$ is more in line with the laws of the experimental points, and the model formula is as follows:

$$
\mu=(3.127 E 12-2.109 E 11 x \ln (T-286.048)) \exp (-25.10 w)
$$

The fitting results show that when the moisture content of sludge is constant, the parts of Eq .4 and Eq. 5, that is to say $\exp (-49.64 w)$ and $\exp (-25.10 w)$ is a constant, so that the relationship between apparent viscosity of municipal sludge and temperature is ExpDec1, a kind of single exponential decay. Similarly, the relationship between apparent viscosity of dyeing sludge and temperature is $\log 3 \mathrm{P} 1$, a kind of logarithmic decrement. Both of them show the tendency that the apparent viscosity of sludge decrease with the increase of temperature, which is similar to the previous research.

In order to verify model the apparent viscosity $\mu$ of sludge, that is, to verify the Eq. 4 and Eq. 5 . The Fig. 9 and Fig. 10, which demonstrate difference between the fitted value of model and experimental value of both two kinds of sludge at the common temperature of $15^{\circ} \mathrm{C}, 50^{\circ} \mathrm{C}$ and $90^{\circ} \mathrm{C}$, are verified, show the verification at different moisture content.

From Fig. 9 and Fig. 10, experimental values and model fitting values of both two kinds of sludge are relatively close to each other, and it is found that the maximum error is less than $25 \%$ after calculating. Considering the neglect of some effects on the coefficient of $f$, it is thought to be mainly influenced by the temperature, so what is obtained from the model is acceptable.

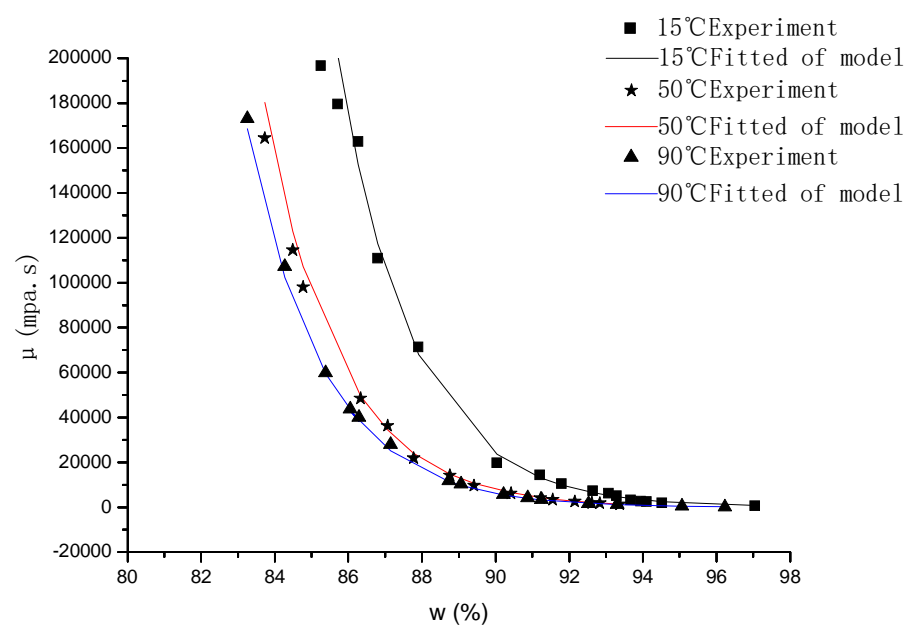

Fig. 9 Experimental and fitting values of municipal sludge versus wet basis moisture content. 


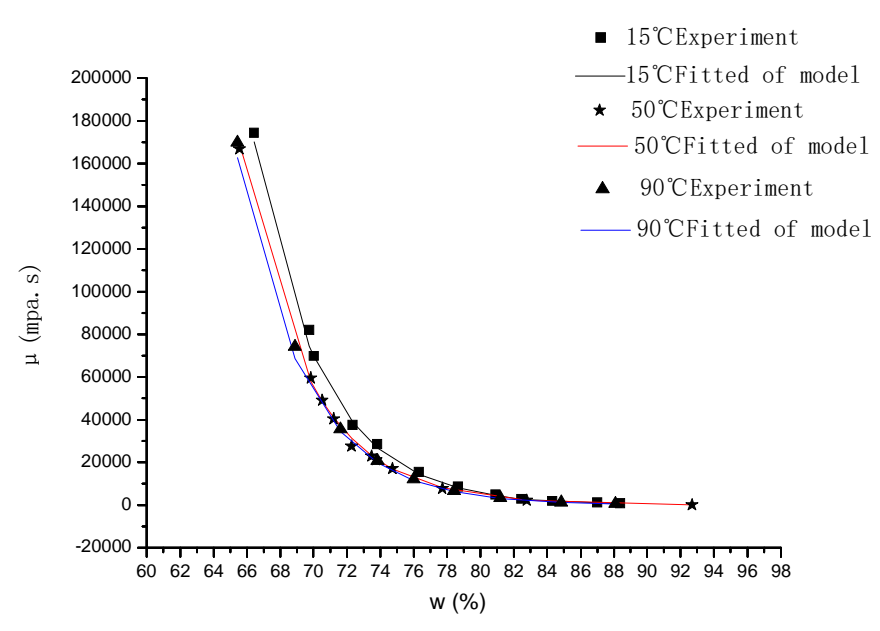

Fig. 10 Experimental and fitting values of dyeing sludge versus wet basis moisture content.

\section{Conclusions}

(1) Under the same wet basis moisture content, due to the different content of organic matter, the apparent viscosity of municipal sludge is much larger than dyeing sludge's, and the difference increases with the decrease of respective moisture content of the two kinds of sludge; inflection point of increase is different for different kinds of sludge.

(2) The apparent viscosity of sludge shows exponential growth in the form of $\mu=f \exp (g w)$ with the decrease of the moisture content. For the same kind of sludge, coefficient $g$ is constant value, and the values of municipal sludge and dyeing sludge are-49.64 and -25.10. In addition, coefficient $\mathrm{f}$ is only related to the temperature for the same kind of sludge, the models of coefficient $f$ of municipal sludge and dyeing sludge are accordance with ExpDec1 model and Log3P1 model respectively.

(3) The model equations between apparent viscosity of municipal sludge and dyeing sludge and moisture content and temperature are obtained as follows respectively:

$$
\begin{aligned}
& \mu=\left(5.392 E 22+2.766 E 28 x \exp \left(-\frac{T}{26.623}\right)\right) \exp (-49.64 w) \text { and } \\
& \mu=(3.127 E 12-2.109 E 11 x \ln (T-286.048)) \exp (-25.10 w)
\end{aligned}
$$

\section{Acknowledgments}

The authors are grateful for the support of the Scientific Research Plan Project of Guangdong Province (2014A020216005), and the Key Laboratory of Efficient and Clean Energy Utilization of Guangdong Province (2013A061401005) .

\section{References}

[1] X. H. Dai, Present situation and thinking of urban sludge treatment and disposal in China. Water Wastewater Eng. 38(2) (2012) 1-5.

[2] T. Tuncal, Evaluating Drying Potential of Different Sludge Types: Effect of Sludge Organic Content and Commonly Used Chemical Additives. Drying Tech. 28(12) (2010) 1344-1349.

[3] H. C. Li, Statistical dynamic features of sludge drying systems. Int. J. Therm. Sci. 46(8) (2007) 802-811.

[4] D. Fytili, A. Zabaniotou, Utilization of sewage sludge in EU application of old and new methods-A review. Renew. Sustain. Energ. Rev. 12(1) (2008) 116-140.

[5] Q. Chang, Colloid and interface chemical are controlled by the water quality. Beijing: Chemical industry press, 2013. 
[6] B. Lou, S. H. Zhao, X. F. Long, Wall-sticking characteristics of paper sludge. Biotech. 10(7) (2014) 1821-1826.

[7] M. Wu, X. Y. Zhao, et al. Research on characteristics of municipal sewage sludge and its pipeline transportation technology. Chinese J. Environ. Eng. 2(2) (2008) 260-265.

[8] Q. J. Wang, Ch. Ch. Tang, Method of Calculating the pressure of pumping sludge with low moisture content. J. East China Jiao tong University, 18(3) (2001) 90-92.

[9] Z. Zhou, C. Xing, et al. Study on rheological characteristics of membrane concentrated sludge. Tech. Water Treatment. 39(3) (2013) 54-56.

[10]D. Leighton, A. Acrivos, The shear-induced migration of particles in concentrated suspensions. J. Fluid Mech. 181(-1) (1987) 415-439.

[11]M. F. Wang, et al. Simulation and assessment of sludge concentration and rheology in the process of waste activated sludge treatment. J. Environ. Sci. 21(12) (2009) 1639-1645.

[12]M. M. Sozanski, E. S. Kempa, K. Grocholski, et al. The rheological experiment in sludge properties research. Water Sci. Tech. 36(11) (1997) 69-78.

[13]F. Yang, A. Bick, S. Shandalov, et al. Yield stress and rheological characteristics of activated sludge in an airlift membrane bioreactor. J. Membr. Sci. 334(1) (2009) 83-90.

[14]H. Hasar, C. Kinaci, A. Ünlü, et al. Rheological properties of activated sludge in a sMBR. Biochem. Eng. J. 20(1) (2004) 1-6.

[15] V. Lotito, L. Spinosa, G. Mininni, et al. The rheology of sewage sludge at different steps of treatment. Water Sci. Tech. 36(11) (1997) 79-85.

[16]L. Wolny, P. Wolski, I. Zawieja. Rheological parameters of dewatered sewage sludge after conditioning. Desalinat. 222(1-3) (2008) 382-387.

[17]G. W. Gu, et al. Membrane bioreactor_-research and application in wastewater treatment. Beijing: Chemical Industry Press, 2002.

[18] M. Mori, I. Seyssiecq, N. Roche. Rheological measurements of sewage sludge for various solids concentrations and geometry. Proc. Biochem. 41(7) (2006) 1656-1662.

[19] G. Laera, C. Giordano, A. Pollice, et al. Membrane bioreactor sludge rheology at different solid retention times. Water Res. 41(18) (2007) 4197-4203.

[20]E. Nicky, M. Flora, Z. Dwen, H. M. Kiet. Predicting the apparent viscosity and yield stress of digested and secondary sludge mixtures. Water Res. 95 (2016) 159-164.

[21]F. Markis, J. C. Baudez, R. Parthasarathy, et al. Predicting the apparent viscosity and yield stress of mixtures of primary, secondary and anaerobically digested sewage sludge: Simulating anaerobic digesters. Water Res. 100 (2016) 568-579. 